\title{
The New Ways to Raise Capital: An Exploratory Study of Crowdfunding
}

\author{
Matteo Rossi ${ }^{1}$ \\ ${ }^{1}$ DEMM Department, University of Sannio, Benevento, Italy \\ Correspondence: Matteo Rossi, Assistant Professor of Corporate Finance, DEMM Department, University of Sannio, \\ Benevento, Italy. E-mail: mrossi@unisannio.it
}

Received: January 8, 2014

Accepted: January 22, 2014

Online Published: March 30, 2014

doi:10.5430/ijfr.v5n2p8

URL: http://dx.doi.org/10.5430/ijfr.v5n2p8

\begin{abstract}
Purpose - Paper aims is to describe, analyze and to increase the knowledge of the emerging crowdfunding phenomenon. This can be defined as the practice of funding a project or venture by raising a lot of small quantities of money from a huge number of people. Even though the number of academic studies has been increasing, the coverage of the population is relatively weak and not well understood by entrepreneurs and individual investors.

Design/Methodology/Findings - The research can be classified as an exploratory research. It focuses on how the crowdfunding works. The research addresses the following research questions: What is crodwfunding? Which are the main characteristics of this phenomenon? Wihic are the principal strengths and the main weaknesses of crowdfunding? The findings expose purposes, characteristics, roles and tasks, and investment size of crowd-funding activity.
\end{abstract}

Practical implications - The findings have implications for service managers interested in managing crowd-funding initiatives and to improve the activity of the consumers.

Originality/value - The paper analyses a new emergent phenomenon. It aims to define the user/costuemr's role from co-creation to investment.

Keywords: fundraising, crowdfunding, crowdsourcing, company's life cycle, financing start-up

\section{Introduction}

The availability of money is indispensable for the functioning of an enterprise. The finance department is the corporate function which deals the phase of funding and as part of the management cycle has as its object the dynamics of capital.

The object of the finance function can be traced back to three questions:

- What is the total volume of capital means that firm must commit?

- What specific investments the firm has to make?

- Which are the sources where capital must be obtained?

The lack of capital is ne of the most important obstacle to growth that can't be always satisfied by recourses of othe people (family and friends) or financial operators. The management of the capital factor, since the acquisition to the time of its use, will require a decision-making focused on quantitatively and qualitatively capital resources observed both in their origin - sources - and in their destination - uses. Funds can differ in the different stages in a company's life cycle (Figure 1). 


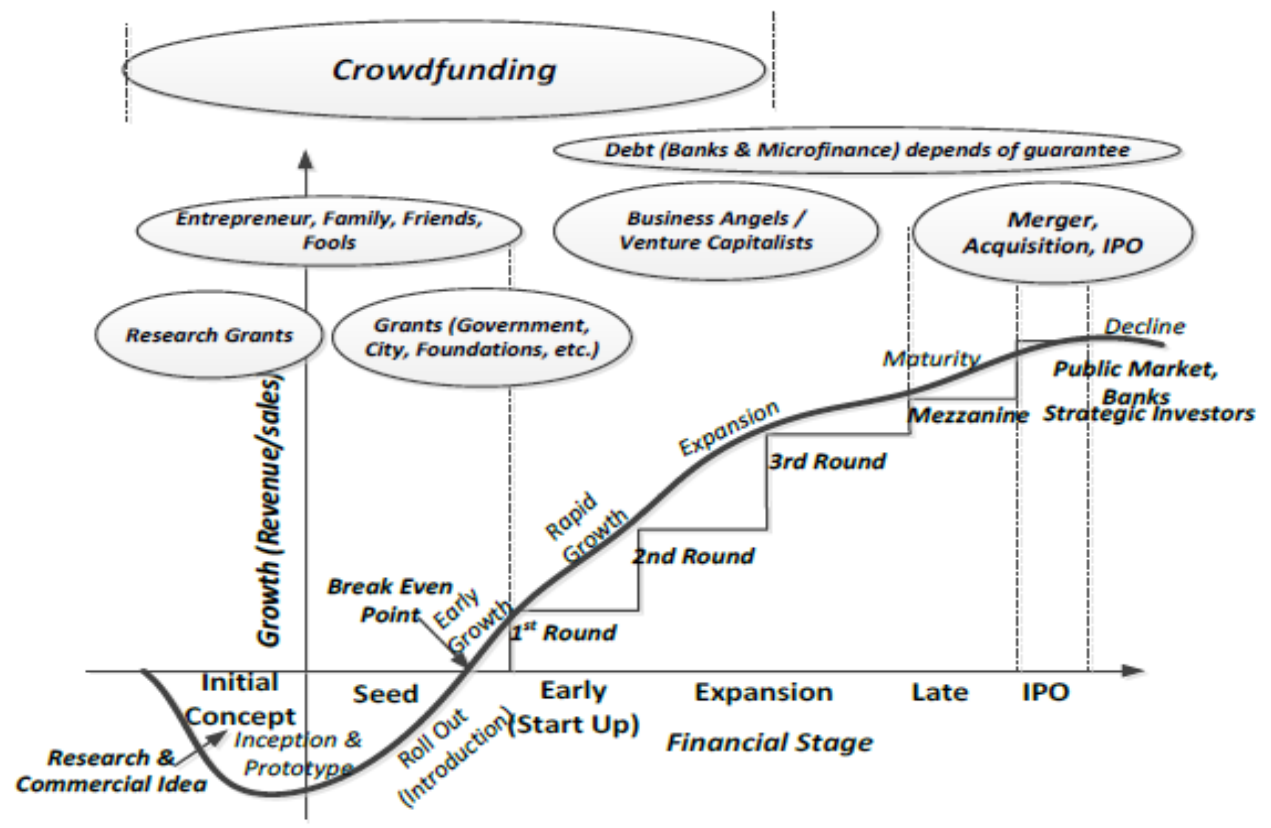

Source: Lasrado, 2013

Figure 1. New venture financing lifecycle

Seed financing is important to design and develop a business idea before a company has realized the start-up phase. At this phase, family of entrepreneur and/or business angels are the main investors of new business. Start-up financing is used for product development and initial marketing. Businesses may still be in the creation phase or have just started operations and have not sold their product commercially. At this stage, money are important to realize R\&D of the new idea/product. This is especially true in technology sectors (ICT, life sciences and biotech). When the product has taken form, a certain number of Venture Capitalists will join the firm: they want to setting up the business (Note1). In Post-created stage, firm has developed its product and it require more financial resources to begin making and selling it. Firm has not yet generated profits. The step of Expansion-Development is a period of high progression. In this stage capital is used to increase production, to develop new services/products, to finance acquisitions and/or to increase the working capital of the business.

Capital requirements can be tackled in different ways, so it is important to know the differences. Sources of financing can generally be divided into two main groups: equity and debt.

When money is invested in equity, it goes directly into the capital of the company Investors receive shares for their investment, and they have a control of the company, but at the same time they tolerate an high risk.

Those who give finance for debt remain extern to company. They are linked to the firm by a contractual agreement. They have a lower risk thanks to collateral and seniority of their claims over equity. However, startup companies cannot accede to debt finance, since they do not have the collateral nor stable cash flows to ensure their debt (Berger and Udell, 1998).

The paper structure is: section two introduces a literature review on crowdsourcing and crowdfunding. The third section defines and analyses the phenomenon. Section four describes different types of crowdfunding, its risks and its findings. In the section five there are conclusion and managerial implications.

\section{From Crowdsourcing to Crowdfunding: A Literature Review}

The choice of financing is driven by the costs of the sources which are primarily determined by costs of solving the asymmetric information problem and the expected costs associated with non-payment of debt. Asymmetric information costs arise from collecting and analyzing information to support the decision of extending credit, and the non-payment costs are from collecting the collateral and selling it to recover the debt. 
The main forms of financial sources are represented by:

- Bank loan and other forms of bank instruments (Overdraft, Discount of effects in the short term, Factoring, Finance leases, Discount of effects in the medium/long term);

- Stock market;

- Venture Capital, Private Equity and Business Angels.

In the last few years a new form of investment interested a increasing number of intiatives and firms: crowdfunding. In crowdfunding people pool their money together, in order to invest in and support efforts initiated by other people or organizations. The idea that some people may decide to pay for producing and promoting a product, and tolerate the risk, represents an additional step in the evolution of consumers' roles. Being new phenomena, crowdfunding and its consequences for company and customers are not completely understood (Ordanini et al, 2009). A problem for new entrepreneurs is to attract capital. In fact, the lack of cash flows and the significant information asymmetry (Cosh et al., 2009). New firms that require smaller amounts to start with, need to depend on friends and family or own savings. Recently, some entrepreneurs have started to rely on the internet to seek financial funds from the crowd. In this conditions crowdfunding permite to raise capital for innovative investments as well as for starting up new ventures (Schwienbacher and Larralde, 2010). The principle of this phenomenon are older but only with the development of the technology it spreads because the typical mode of communication and use of crowdfunding is internet. The use of the internet to raise money through small contributions can be a revolution in small-business financing. In fact, small firms who can have difficulty to obtain capital, have access to anyone in the world (Bradford, 2012).

Crowdfunding is the system to finance a project or a firm by a group of people instead of professional parties like banks or venture capitalists (Note 2). Also, single investor can finance investments indirectly, with the interventation of financial intermediaries. In contrast, crowdfunding don't require intermediary.

Actually, there are about 500 crowdfunding platforms with some differences in the services provided. The leader of this secotr is Kickstarter. Since April 28, 2009, over $\$ 500$ million has been assured by more than 3 million people, funding more than 35,000 creative projects.

Also politicians - like Obama, Presdient of US - have been collected donations from the general public (Howe, 2008).

Brabham (2008) said that the composition is the strength of crowds. In fact this is the most important factor in solving problems of firms. Surowiecki (2004) explains that the 'wisdom of crowd' is that the crowd may build up their own solution using others' propositions and hence end up having better solutions overall. Besides, crowds may be more efficient than individuals (Howe, 2008). This concept is well expressed by Lévy (1997): he spoke about a collective intelligence. in fact, each person knows something (a part of complex problem). He sustain that the solution is to share competences, because all knowledge resides in humanity.

There are a lot of example of crowdsourcing. We use crouwdsource without thinking about it. Wikipedia is one of the most importnat example of crowdsourcing (Anderson, 2006).

Another antecedent of crowdfunding is microfinance, which involves lending small amounts of money, typically to poorer borrowers (Mincer, 2008). There is a difference between microfinance and crowfund: in microfinance is important the beneficiary, very small firms, in crowdfundign is important the donor, small contributors for a common aim.

Crowdfunding sites bring together investors buying securities and the entrepreneurs selling them and facilitate execution of the sales much as a securities exchange would, a trading system must, among other things, $<<$ bring] together the orders for securities of multiple buyers and sellers $>>$ (Dolfato and Jones-Lepidas, 2001: 372).

The power of crowds is not just gaining access to ideas, it's also very much about using the collective wisdom as a sorting and leading indicator mechanism, which allows for scalability (Rubinton, 2011).

In the brief time since internet-based crowdfunding appeared, it has grown exponentially. Crowdfunding is becoming a huge business, with $<<$ a steady parade of services joining the fray $>>$ (Bennett, 2011).

The principal insutry interested to crowdfunding is the entertainment industry (Kappel, 2009), but it interest all types of activities (book publishing, gaming, music, journalism, or agriculture).

It's necessary to establish that crowdfunding is not a US phenomena, because there are a lot specific sites also in other countries suche as Europe in generale, Hong Kong and Brazil. 


\section{Crowdfunding: An Analysis of an Older Phenomenon}

The basic idea of crowdfunding phenomenon is to raise money through relatively small contributions from a large number of people (Bradford, 2012). Using the Internet, an entrepreneur can communicate with little expenses to millions of potential investors. Firms haven't an intermediary: anyone with a good idea can become an entrepreneur, anyone with a little amount of money can become an investor (Figure 2).

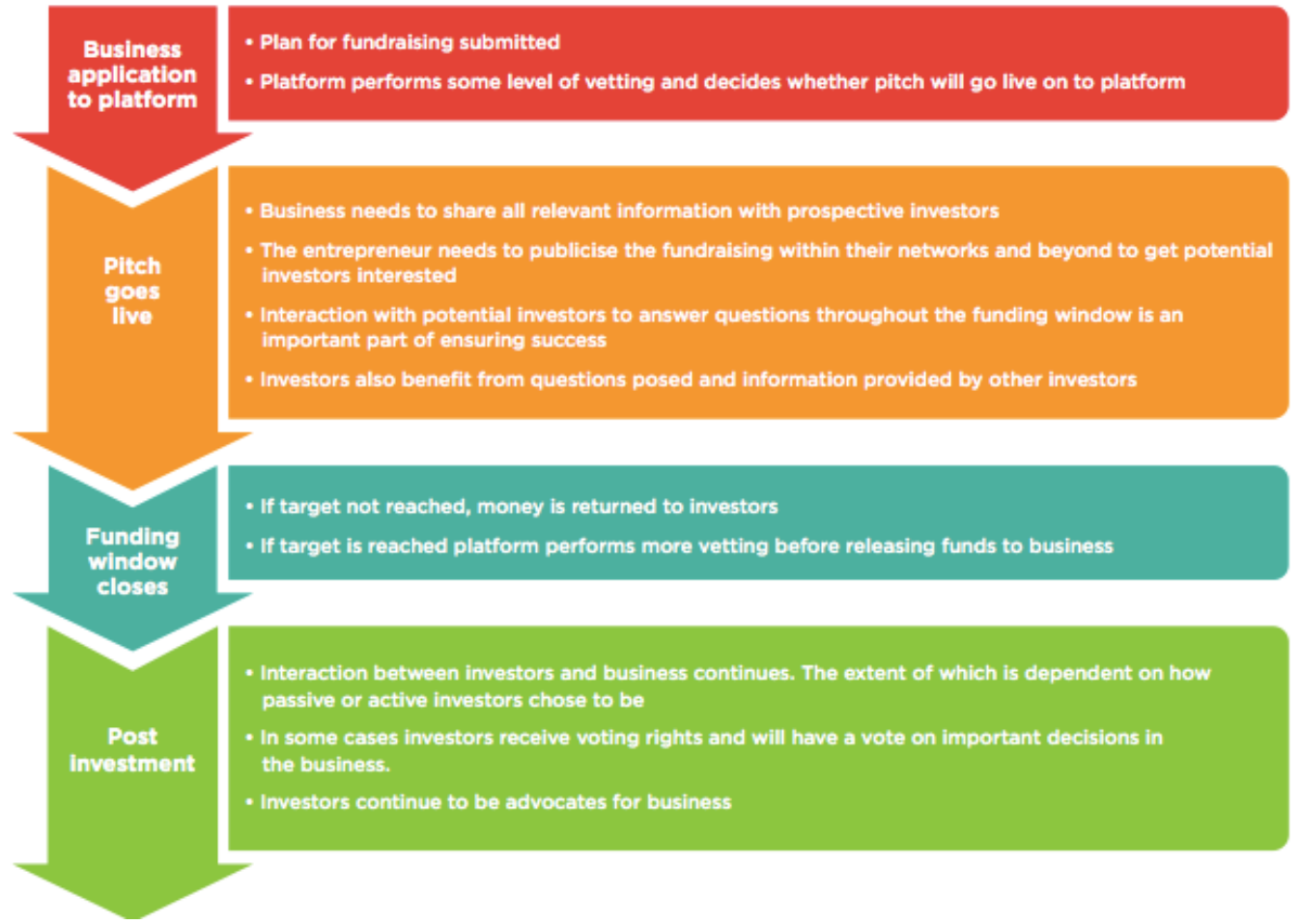

Figure 2. How equity-based crowdfunding works

Source: Vidra E., 2012.

The crowdfunding process is simple: the aspiring entrepreneur publishes a request for money on a crowdfunding website. New entrepreneur must describe his idea, and wah he wants to do with funds. The new idea is presented with a business plan. New firm must specify what people who finance the business will receive for contributions. Frome the other side investors browse through business' list, and, if they find someone that interests them, they can contribute with few euros. Crowdfunding sites realize a complex activity. They favour to bring entrepreneurs and investors together, but they provide a complex platform for investors and entrepreneurs to negotiate; they facilitate the transmission of funds and investment documents back between investors and firms.

This (not) new phenomenon isn't based on immaginaries properties that prevent investors from losing money just like other investors. However the cost for "stockholders" of a crowdfunding exemption is likely lower. Investors are already contributing substantial amounts of money to unregulated crowdfunding offerings, although not for securities. Those investments are subject to the same risk of loss as crowdfunded securities, but do not offer the upside potential of a securities investment. Allowing entrepreneurs to sell securities would, therefore, be a net gain to investors, increasing the possibility of gains without any increase in the risk.

Investing in small businesses is risky, because these investments are illiquid. Small businesses, especially new firms, can fail more than established companies. Crowdfunding offerings are typically rather small but are not necessarily limited to these. The rigid institutional structures previously required to organize economic action are, in many cases, no longer necessary.

Crowdfunding permits to a firm to publish its request for funding to the world, making it easier to connect extra capital and route it to those who need it most. A potential positive effect is the propensity of groups to produce an accurate aggregate prediction about market outcomes as identified by author James Surowiecki (2004) thereby placing financial backing behind ventures likely to succeed. 
The power of crowds is linked not only with the access to ideas, but also with use of collective knowledge as a leading indicator tool, which allows for scalability (Rubinton, 2011).

There aren't only financial benefits for firms. Bardford (2012) underlines other important benefits:

a. A persuasive idea can raise a producer's profile and offer an improvement to their reputation;

b. Crowdfunding is an important mode for new firms to develop proof for their product, and to test if there is a potential market;

c. It creates a form where project initiators can participate with audiences;

d. Offering a test on content to project supporters as a part of the funding incentives provides the project initiators with instant access to good market testing feedback.

Bradford (2012) also highlights potential risks:

> Failure to meet campaign goals or to generate interest result in a public failure;

$>$ Content producers can be reluctant to publicly announce the details of a project before production ;

$>$ There is a risk that if the same network of supporters is reached out to multiple times, that network with eventually cease to supply necessary support;

$>$ that without a regulatory agenda, the probability of a scam of abuse of funds is high.

In many cases, as demonstrate from some researches in social psychology, investors make investment decisions based on emotion rather than a financial evaluation.

New technological revolution - such as web 2.0 - offers new opportunities to consumers. They can create new contents. They can interact between them, and they can involve in the service provision itself. For these reasons Bendapudi and Leone (2003) sustain that while customer participation may contribute to efficiency and a product customization, it also has some disadvantage: e.g. an increased uncertainty and a personal responsibility over the outcome.

One of the most important aspect of crowdfunding is that customers, with their evaluation process and their funding support, are the key actors who make possible the development of idea. Another fundamental ascpect of crowdfunding is that a huge number of people participate in decision of what should be offered.

However, crowdfunding models require to participants to not only contribute with knowledge, but also to have a promotional role in support of the initiatives being crowdfunded. In fact, they can use virtual communities to generate a process of collective value creation.

The most important difference between crowdfunding and institutional investors is the background. In fact, unlike business angels or venture capital funds, crowdfunders might not have knowledge and capabilities about the firm. However, the wisdom of the crowd can at times be more efficient than teams of expert in specific problem solving. For this reason, crowd would be more efficient than a few investors. Furthermore, the risk of by crowdfunders is smaller. This reduced risk is linke not only to the amounts that they provide individually, but also because their evaluation is linked to their future use of product. In fact, they become consumers once the product has been realized. Thay also have an incentive to disseminate the information about the product. This last condition is very importnat in the stage of dissemination: institutional investor must realize an important advertisement campaign if the venture were financed by a few, larger investors, corwdfunders are the first advertising channel for new product.

The power of crowds isn't a simple access to ideas, but it also linked to the common use of wisdom. Lehner (2013) sustains that every person has an advantage over all others becase he/she has informations, but benefic use can be realized only with a cooperation in which the decisions are made with his active cooperation.

The most important trait of crowdfunding is that people are the key palyers who make possible the generation of new idea, the creation of a new service-product. But as undelined by Ordanini (2009), crowdfunding requires an active participation of all people involved in promoting the new inititatives.

Therefore, crowdfunding is a revolutionary mechanism. In fact, users - participating to product development contribute to create value for firm. Moreover, for Schwienbacher and Larralde (2010) this permits the company to reduce the time and the costs for develop a new product. This new model has the important result of a better client acceptance, and increases the customers' perception of product. 


\section{Typologies of Crowd Fund and Findings}

In crowdfunding people want to share with other people idea and projects. They like that other users are close to them, emotionally or geographically. It's possible to define different business models for crowdfunding. In fact, they can be classified considering the type (Crowdsourcing.org, 2012)of rewards offered to the participating crowd (Figure 3):

$>$ reward-based (i.e. website platforms based on an object return), about 44 per cent of the total platforms, animate only 700,000 Euros;

$>$ lending-based, such as projects in the third sector that also comes to form capital of 10 million, about 15 percent;

$>$ simple donations, about 28 percent of the market;

$>$ equity-based, where every investor acquires firm shares, about 14 per cent. This is a real investment, and as such it has high risks.

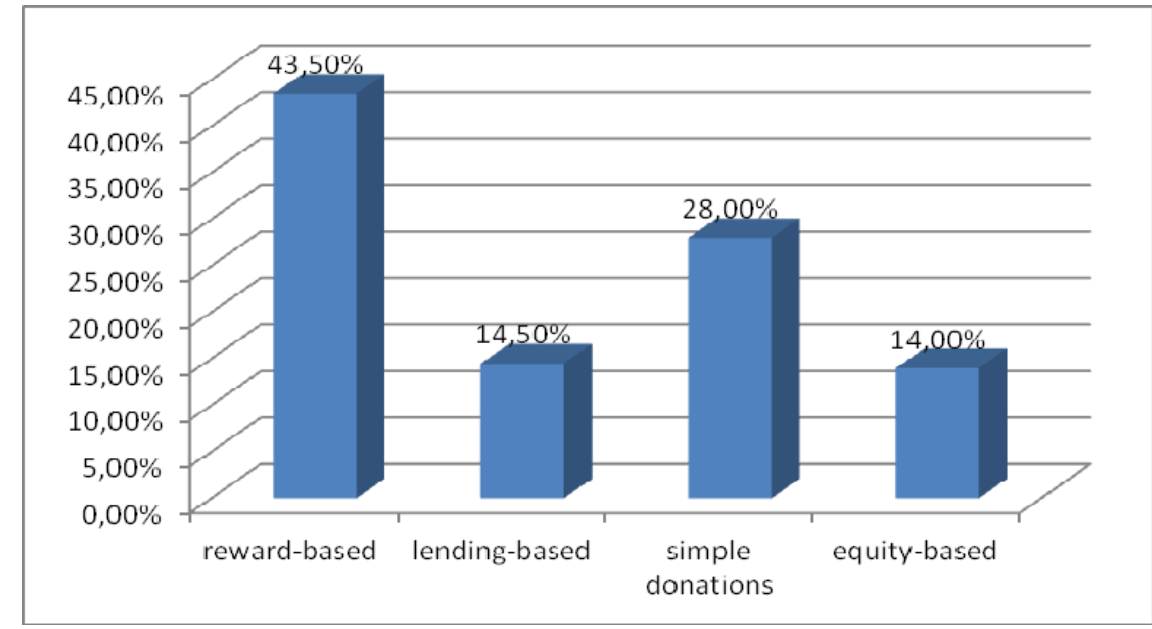

Figure 3. Typologies of crowdfunding

Source: Crowdsourcing.org, 2012.

One fundamental step is to regulate guarantees and obligations between platforms, investors and firms. Some people have an interest to invest in projects that share their own values, that can create jobs in a local area and community. Others have a Knowledge of a market, a project or business. They want to bring funds and expertise for the success of the project. They are similar to institutional investors.

Reward-based crowdfunding is used for creative firms or smaller goods, where pre-financing for production is necessary for a demand-test. If a consistent number of people is involved in this phase, the entrepreneur realises two important goals: a market validation, and acquisition of funds to financing his activities.

Lending based crowdfunding offers funds to an entrepreneur that wants money but doesn't want other shareholders.

Donation-based crowdfunding is used for not-for profit organizations. They use this tool for fund projects and core costs, but it can also help to finance creative activities and common activities.

Equity-based crowdfunding offers an additional route to raise monwy for any firm, with all associated risks. In this case there is an high risk. This risk is associated to information asymmetries and lack of publicly data. However with the the publication of all necessary project details, some of this risks can be mitigated (never deleted).

Lambert and Schwienbacher (2010), in their empirical research, finds that $22 \%$ of their sample of crowdfunding initiatives relies on donations. They also identify that a big number of initiatives offer some form of rewards to their investors; these rewards can take various forms. However, most of them do not offer possibility to investors to be involved in the initiative. Entrepreneurs that seek passive funds by the crowd therefore are interested in raising money. Thesy don't want to use the crowd as customers or giving up firm control. 
Other firms offer investors to become active in their idea. This can be transformed in important feedback for the entrepreneur. In fact, he has data on potential market demand and good characteristics that the market may prefer most. Also, the active involvement may be structured like crowdsourcing.

Each remuneration scheme may generate different forms of information and may vary in terms of credibility of the signal. For example, while pre-ordering at discount can be an important signal for a pre-specified product, the participation of investor in the profit sharing can test their market sentiment in general. In fact, not all investors may become consumers. Make investors as active shareholders, give them voting rights, and may provide to the entrepreneur information for thinking his product and selecting the optimal market target. All these actvities could be done without a website, but it requires an higher cost in time, money and efficiency. The use of web allows to the crowdfunding industry to grow rapidly (Figure 4).

Crowdsourcing.com (2012) show that equity-based crowdfunding was the smallest sector market in 2012. Its value is only $€ 89$ million. The main reason is that start-ups, particularly in the US, are able to raise fund from institutional investors. In the next years, the distribution of funds raised from different typologies of crowdfunding is likely to shift.

An analysis based on Crowdsourcing.com data shows that the average of funds raised from a project depends on the kind of this In fact, the average amount of money:

$>$ for a Donation project is $\$ 664$;
$>$ for a Lending project is $\$ 5,587$;
$>$ for a Reward project is $\$ 4,076$;
$>$ for an Equity project is $\$ 84,597$.

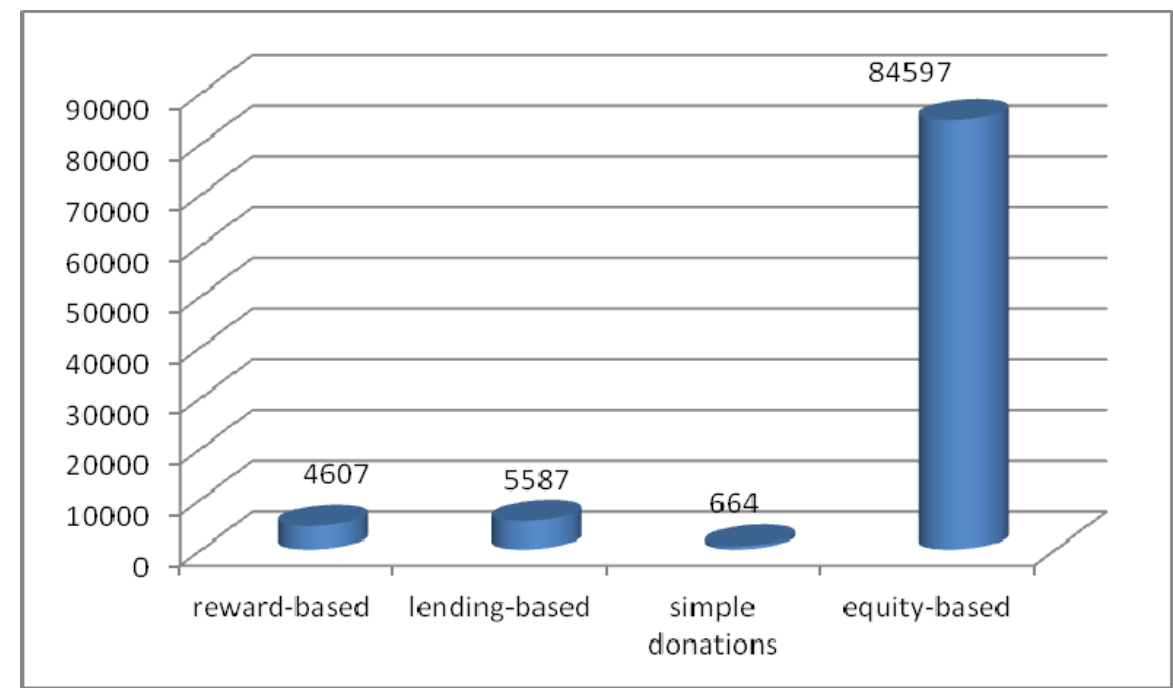

Figure 4. Average funds raised

Source: Croudsourcing.org, 2012.

For a future development of crowdfunding in US, it's necessary an intervention of Securities and Exchange Commission. Particularly, it's necessary to define rules for allowing US entrepreneurs to raise funds by selling shares of their firm more easily to non-institutional investors.

Another posible classification of crowdfunding is:

$>$ classic crowdfunding, when a project has yet to be born in search of funds;

$>$ partial crowdfunding, a project that has a partial part of funds, but it is already looking for more money;

$>$ presale crowdfunding, project that is near to be born and that seeks funds for printing support;

$>$ distribution crowdfunding, project already realized and printed in search of new funds.

If we analyze the most important crowdfunding categories for 2012, it's possbile to distinguish: 
$30 \%$ social causes;

> $16.9 \%$ business and entrepreneurship;

$>11.9 \%$ film and performing arts;

$>7.5 \%$ music and recording arts;

$>5.9 \%$ energy and environment;

$>28 \%$ other.

Previous crowdfunding experiences demonstrate that the average timeframe of succesfull campaign is about 8-9 weeks from its launch. The analysis of each category demonstrates that equity-based Crowdfunding raises the largest amount of money per project. Particularly, equity-based crowdfunding produce the largest amount of fund raised on a per-project basis. $21 \%$ of the money raised by equity-based platforms were raised for projects that drew at least $\$ 250,000$.In contrast, about $6 \%$ of the money on equity-based crowdfunding platforms were raised for projects that drew less than $\$ 10,000$. These data show that big funds can be raised via equity-based crowdfunding platforms. So crowdfunding shows to be a valide tool, alternative to institutional investors for raising fund for small and medium start-ups.

The process of disinvestment can be mangadef in different ways. Some investors choose to be involved in the strategy process of the firm. Other funders will continue to be involved in the business at the post-investment stage: e.g. donors can provide the firm with advice on topic ranging from firm strategy to product pricing. However, for entrepreneur managing a huge number of investors can be difficult. There are more difficulties are more for the platforms which assign voting power to investors, because this can be even more difficult to manage, if not only for purely logistical reasons.

The key elements for a succesful project of crowdfunding are:

1. to clarify aims, targets and timeline;

2. to select the right website;

3. to choose the right rewards and put in a good communication plan.

Proponents of the crowdfunding system sustain that it allows to finance ideas which don't receive attention to conventional financial institutions. With corwdfunding, firms not only can obtain funds for seed-financing, but they can obtain benefit from word of mouth of potential customers.

Surowiecki (2004) identifies another important positive effect: the propensity of groups to realize an "accurate aggregate prediction" about market results.

For these reasons, it's possible to consider some important benefits that crowdfunding offers to firms (Prive, 2012):

$>$ It guarantees access to capital. At an early stage, a firm can think that only accredited investors (banks, business angels, etc.) can give it funds, outside of their network;

$>$ It permits to develop and test a concept. Crowdfunding permtis to show business has received a market validation at an early stage. This is important to convince investors;

$>$ It hedges risk. For a startup the begining is a risky and challenging trip, and crowdfunding helps entrepreneurs to manage this journey;

$>$ It allows a brainstorming. SMEs can have difficulties to cover all the holes that a venture might have at a start-uop stage. With a crowdfunding activity, the entrepreneur can receive comments, feedback, and ideas from the crowd;

$>$ It is a marketing tool. A good crowdfunding campaign is a good instrument to introduce a firm's mission to the market;

$>$ It introduces potential loyal clients. With a crowdfunding campaign entrepreneur presents a firm and product. It gives him the possibility to share the message and the purpose behind a product. Investors who sustain entrepreneur's campaign are ones that believe in the firm success;

$>$ It is more easier than traditional tools. Requesting of a loan is one of the most principal process that every firm realizes. This process is very hard, especiallyfor a start-up; 
It makes possible the pre-selling. Wih a crowdfunding campaign an entrepreneur has the ability to pre-sell a service-product that isn't on the market. This is a good way to evaluate users reaction. Before this reaction the entrepreneur can decide if to pursue in developing the product idea;

$>$ It is free. Crowdfunding platforms haven't fee, if the entrepreneur not achieve the funding aim.

For the entrepreneur, crowdfunding represent an opportunity to establish a direct link with customers. In fact, crowdfunding is an effective way to mesaure if an idea, a product or a service has appeal. Most important is the time in which the entreprenuer is able to make this evaluation. When an entrepreneur combines different approaches, he can fund different stage of life-cycle of product.

In the last few years, crowdfunding is growing very fast. Acatually, it is a phenomenon all over the world, but North America and Europe dominated this industry: they raise 59\% and 35\% of worldwide capital (Figure 5). In 2012 $€ 1.23$ billion of funding raised, came from North America and $€ 727$ million was raised in Europe. The share of the European market in terms of volume of money raised is dominated by the United Kingdom (63\%), followed by Germany, Poland, France, Italy and Spain.

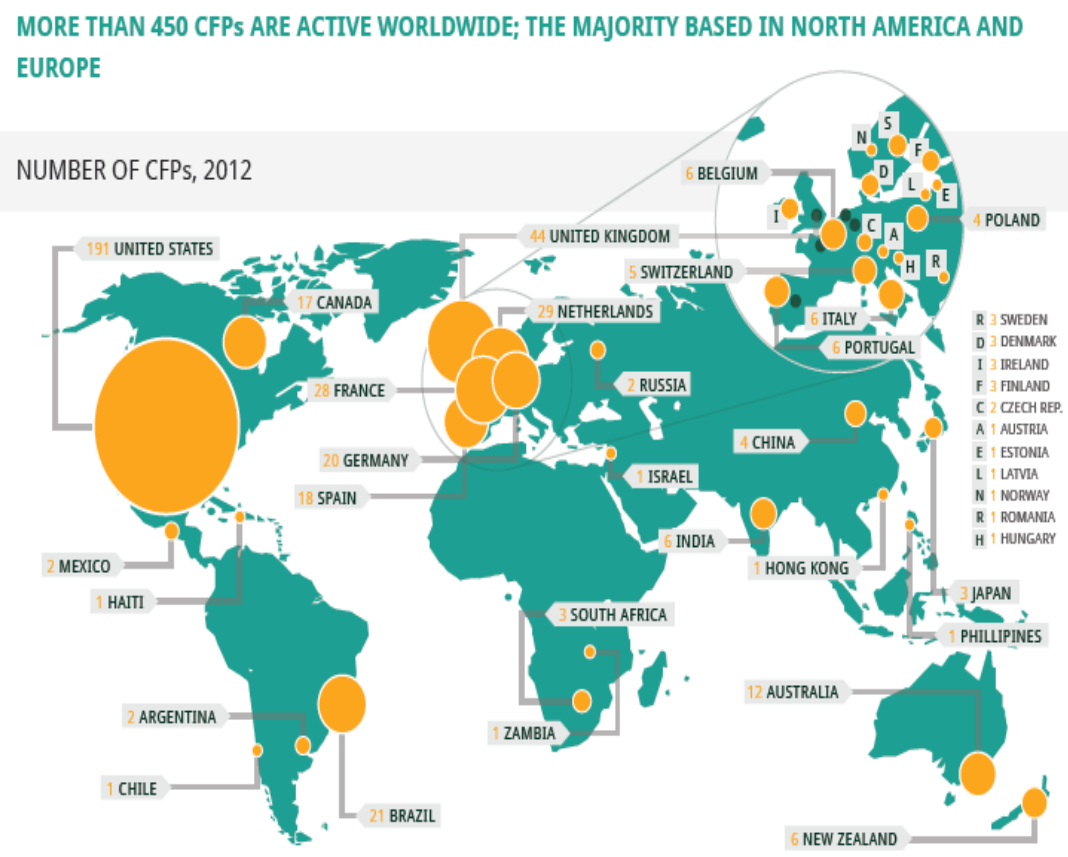

Figure 5. Number of crowdfunding platforms all over the world

Source: Crowdsourcing.org

\section{Conclusions}

The principal objective of a crowdfunding investment is to raise money for a project. The basis idea in a crowdfunding initiative is that funds do not come from professional investors, but form a huge number of people, and each member of this crowd contributes with a small fund. The strenght of crowdfunding is the collective intelligence. Schwienbacher and Larralde (2010) affire that a crowd may be more intelligent that individuals. In a croawdsourcing system each member has a possibility of building knowledge on skills of others. So, as Surowiecki (2004) emphasizes, the wisdom-of-crowds predicts that the free judgments of a crowd will be relatively accurate, even if most of the people are ignorant and error prone (Surowiecki 2004).

Generally, scholars define three main factors for the success of crowdfunding:

$\checkmark$ the lack of funds generated by the global crisis. Today, there are a lot of difficulty to raise funds for entrepreneurial projects;

$\checkmark \quad$ the evolution of a new web marketing based on 2.0 technologies: This new technologies have made more easier to develop the web platforms used for interactions; 
$\checkmark \quad$ the success of the crowdsourcing phenomenon (e.g. Wikipedia).

These elements explain the success of the crowdfunding as a whole, but they doesn't explain the success of the single entrepreneurial idea.

Therefore crowdfunding can be considered also as a promotional tool. It is a way to get to know the custoemers, a basis for mass customization. Funders may provide a feedback on the business' product-service; it is a perfect tool to validate idea and products before they enter into the market.

There are some important reasons because crowdfunding can be considered a superior financial tool in comparison to others. It's efficient, it's intelligent, it's democratic and it guarantees a distribution of risks. Moreover, crowdfunding doesn't finish when funds are collected. First of all the entrepreneur has to fulfill all his promises. He must realize the activities, because the community can disappear. He must treat well his community, because:

$\checkmark$ each person can become a lifelong fan of the firm,

$\checkmark$ community can become a source of new idea,

$\checkmark$ people can be potential clients.

For these reasons, it's necessary that entrepreneur invests his time and his efforts in constructing and maintaining the relationship with crowd. To raise fund a crowdfunding system requires to use a very big time. One of the most serious mistakes is to save time that must be dedicate to the involvement in the initiative.

Even if, to collect money is the most important reason of a crowdfounder investor, Schwienbacher and Larralde (2010) sustain that financial motivations aren't that important. Some people have intrinsic and extrinsic motivations. Intrinsic ones are related to pleasure to take part to inovative process, self-satisfaction, etc. Extrinsic motives include external rewards, recognition and learning. For Schwienbacher and Larralde (2010) there are a lot of factors which can be motivation for investors:

$\checkmark$ crowdfunders enjoy a participation in building a new firm,

$\checkmark$ they consider it as a tool for extending their own network and building relationships,

$\checkmark$ crowdfunders consider important the advantages of having access to competences of the crowd.

Crowdfunding offers huge opportunities for diversification, but it requires to define specifi rules. De Buysere et al. (2012) affirme that the sector must develop a title of "qualified investor in crowdfunding" that must be complemented by the obligation of platforms to provide sound and widely accepted risk measures.

Crowdfunding in the actual economic context represent a valid alternative to traditional financial ways of firms. In fact, in a situation like that, where there are a limitate number of institutional investors actually involved in the financing of small and medium start-ups, a limited number of private incubators, universities and some hundreds of informal investors, crowdfunding paltforms seem to go in the opposite direction. It represents an important instrument to give impetus to entrepreneurship, to economic development and job creation.

\section{References}

Anderson, C. (2006). The long tail: Why the future of business is selling less of more. Hyperion.

Bendapudi, N., \& Leone, R.P. (2003). Psychological implications of customer participation in co-production. Journal of Marketing, 67(1), 14-28. http://dx.doi.org/10.1509/jmkg.67.1.14.18592

Bennett, B.O. (2011). Crowdfunding 101: How Rising Startups Use the Web as a VC Firm. Retrieved 5 October 2013, from http://blog.laptopmag.com/crowdfunding-101-how-rising-startups-use-the-web-as-a-vc-firm

Berger, A.N., \& Udell, G.F. (1998). The economics of small business finance: the roles of private equity and debt markets in the financial growth cycle. Journal of Banking and Finance, 22, 613-673. http://dx.doi.org/10.1016/S0378-4266(98)00038-7

Brabham, D.C. (2008). Crowdsourcing as a Model for Problem Solving: An Introduction and Cases. Convergence: The International Journal of Research into New Media Technologies, 14(1). http://dx.doi.org/10.1177/1354856507084420

Bradford, S. (2012). Crowdfunding and the federal securities laws. Columbia Business Law Review. Retrieved 11 October 2013, from http://papers.ssrn.com/sol3/papers.cfm?abstract_id=1916184

Cosh, A., Cumming, D., \& Hughes, A. (2009) Outside Enterpreneurial Capital. Economic Journal, 119(540), 1494-1533. http://dx.doi.org/10.1111/j.1468-0297.2009.02270.x 
De Buysere, K., Gajda, O., Kleverlaan, R., \& Marom, D. (2012). A Framework for European Crowdfunding. Retrieved 30 September 2013, from http://www.crowdfundingframework.eu/index.html

Dolfato, J., \& Jones-Lepidas K. (2001). Annotated British Columbia Securities Legislation. CCH Canadian Limited.

Howe, J. (2008). Crowdsourcing: why the power of the crowd is driving the future of business. Crown Publishing Group New York.

Kappel, T. (2009). Ex Ante Crowdfunding and the Recording Industry: A Model for the U.S.. Retrieved 30 October 2013, from http://digitalcommons.lmu.edu/cgi/viewcontent.cgi?article=1550\&context $=$ elr

Lasrado, L.A. (2013). Crowdfunding in Finland - A new Alterantive Disruptive Funding Instrument for Business. TAMPERE UNIVERSITY OF TECHNOLOGY, Master's Degree Programme in Industrial Engineering and Management. $\quad$ Retrieved 2013 October 2 from http://dspace.cc.tut.fi/dpub/bitstream/handle/123456789/21784/Lasrado.pdf?sequence=3

Lehner. (2013). Crowdfunding Social Ventures: A Model and Research Agenda. Retrieved 25 October 2013, from http://www.ssrn.com/abstract=2102525

Lévy, P. (1997). Collective Intelligence: Mankind's Emerging World in Cyberspace. Helix Books

Mincer, J. (2008). Microlending for Microbankers. Wall Street Journal, March 20. Retrieved 1 November 2013, from http://online.wsj.com/news/articles/SB120597508026550479

Ordanini, A., Miceli, L., Pizzetti, M., \& Parasuraman, A. (2009). Crowdfunding: transforming customers into investors through innovative service platforms. Retrieved 5 October 2013, from http://www.scribd.com/doc/59656556/Crowdfunding-Transforming-Customers-into-Investors-through-Innovati ve-Service-Platforms

Prive, T. (2012). Top ten benefits of Crowdfunding. Forbes, December 10. Retrieved 25 October 2013, from http://www.forbes.com/sites/tanyaprive/2012/10/12/top-10-benefits-of-crowdfunding-2/

Rossi, M., Thrassou, A., \& Vrontis, D. (2011). Financing innovation: venture capital investments in biotechnology firms. International Journal of Technology Marketing, 6(4), 355-377. http://dx.doi.org/10.1504/IJTMKT.2011.045914

Rossi, M., Thrassou, A., \& Vrontis, D. (2013). Open Innovation System and New Forms of Investment: Venture Capital's Role in Innovation. In Vrontis D., \& Thrassou A., (Eds.), Innovative Business Practices: Prevailing a Turbulent Era. Cambridge Scholar Publishing, Newcatle Upon Tyne.

Rubinton B. J. (2011). Crowdfunding: Disintermediated Investment Banking. Retrieved 16 October 2013, from http://www.ssrn.com/abstract $=1807204$

Schwienbacher, A., \& Larralde, B. (2012). Crowdfunding of Small Entrepreneurial Ventures. In Cumming, D. (Ed.), The Oxford Handbook of Entrepreneurial Finance. Oxford University Press.

Surowiecki, J. (2004). The wisdom of crowds. Why the many are smarter than the few and how collective wisdom shapes business, economies, societies, and nations. Doubleday, Anchor.

Vidra, E. (2012). Startup Equity Crowdfunding Grows in Europe (NESTA Report). Retrieved from http://www.vccafe.com/2012/07/04/startup-equity-crowdfunding-grows-in-europe-nesta-report/

\section{Notes}

Note 1. In fact, venture capitalists have interest to invest in technologies firms where growth is expected to be significantly higher than other firms (Rossi et al., 2011)

Note 2. Institutional investors - such as VCs - play an important role for growth of innovative firms in their first sages. They aid new firm not only with a financial contribution, but also with a strategic support for growth (Rossi et al., 2013) 